\title{
Estimating the Surface Air Temperature by Remote Sensing in Northwest China Using an Improved Advection-Energy Balance for Air Temperature Model
}

\author{
Suhua Liu, ${ }^{1,2}$ Hongbo Su, ${ }^{3}$ Renhua Zhang, ${ }^{1}$ Jing Tian, ${ }^{1,4}$ and Weizhen Wang ${ }^{5}$ \\ ${ }^{1}$ Key Laboratory of Water Cycle and Related Land Surface Processes, Institute of Geographic Sciences and Natural Resources Research, \\ Chinese Academy of Sciences, Beijing 100101, China \\ ${ }^{2}$ University of Chinese Academy of Sciences, Beijing 100049, China \\ ${ }^{3}$ Department of Civil, Environmental and Geomatics Engineering, Florida Atlantic University, Florida, FL 33431, USA \\ ${ }^{4}$ State Key Laboratory of Remote Sensing Science, Institute of Remote Sensing and Digital Earth, Chinese Academy of Sciences, \\ Beijing 100101, China \\ ${ }^{5}$ Heihe Remote Sensing Experimental Research Station, Cold and Arid Regions Environmental and Engineering Research Institute, \\ Chinese Academy of Sciences, Lanzhou 730000, China
}

Correspondence should be addressed to Hongbo Su; hongbo@ieee.org

Received 2 February 2016; Accepted 29 May 2016

Academic Editor: Philippe Ricaud

Copyright (C) 2016 Suhua Liu et al. This is an open access article distributed under the Creative Commons Attribution License, which permits unrestricted use, distribution, and reproduction in any medium, provided the original work is properly cited.

\begin{abstract}
To estimate the surface air temperature by remote sensing, the advection-energy balance for the surface air temperature (ADEBAT) model is developed which assumes the surface air temperature is driven by the local driving force and the advective driving force. The local driving force produces a local surface air temperature whereas the advective driving force changes it by adding an exotic air temperature. An advection factor $f$ is defined to measure the quantity of the exotic air brought by the advection. Since the $f$ is determined by the advection, this paper improves it to a regional scale by using the Inverse Distance Weighting (IDW) method whereas the original ADEBAT model uses a constant of $f$ for a block of area. Results retrieved by the improved ADEBAT (IADEBAT) model are evaluated and comparison was made with the in situ measurements, with an $R^{2}$ (correlation coefficient) of 0.77, an RMSE (Root Mean Square Error) of $0.31 \mathrm{~K}$, and a MAE (Mean Absolute Error) of $0.24 \mathrm{~K}$. The evaluation shows that the IADEBAT model has higher accuracy than the original ADEBAT model. Evaluations together with a $t$-test of the MAD (Mean Absolute Deviation) reveal that the IADEBAT model has a significant improvement.
\end{abstract}

\section{Introduction}

Air temperature is a basic variable that is normally measured at the height of 2 or $1.5 \mathrm{~m}$ by meteorological stations. It is not only the primary item of weather forecast but also useful for describing the climate change and energy exchange between the earth surface and the atmosphere $[1,2]$. Air temperature also plays an essential role in physical processes of evapotranspiration, photosynthesis, and heat transfer [3]. As a result, many land surface process models including those in climatology, hydrology, and ecology require air temperature as an input variable [4].
Up to now, air temperature has traditionally but mainly been obtained by meteorological stations. However, these meteorological stations are deployed in a limited number of places and thus can only provide information representing the specific local area and often lack a broad enough representation for the regional areas [5]. In addition, meteorological stations are with a low spatial density that usually cannot satisfy the needs either in scientific research or in practical applications [6]. In order to extend the air temperature from a point scale to a regional scale, many spatial interpolation methods [7], for example, inverse distance weighting (IDW), spline function method, and the kriging interpolation 
method, have been used. However, interpolation results usually cannot reflect the detailed spatial variability, and these spatial interpolation methods would produce large errors, especially for the heterogeneous underlying surfaces $[8,9]$. Hence, the lack of sufficient spatial density and lack of enough spatial representativeness in the ground-based air temperature would lead to an inaccurate estimation at a regional scale [1]. Benefiting from the fast development of remote sensing techniques, spatially distributed information on the underlying surface can be obtained. Remote sensing techniques provide a straightforward and consistent way to estimate air temperature at a regional scale with more details than meteorological data. Many studies attempted to retrieve near surface air temperature by thermal infrared remote sensing data [10, 11]. Methods for acquiring the surface air temperature include the temperature-vegetation index approaches (TVX), the statistical approaches, the neural network approaches, and the energy balance approaches $[3$, $10,12,13]$

The TVX method is a widely used approach based on the correlation between the normalized difference vegetation index (NDVI) and land surface temperature (LST), which form a trapezoid space [14]. This method assumes that the near surface air temperature is approximately equal to the canopy temperature when the vegetation is dense $[1,14]$. Actually, vegetation is with an uneven spatial distribution, and then the air temperature under the condition of partial vegetation can be estimated by extrapolating the air temperature of full coverage [15]. A unique advantage of the TVX method is that it only needs the LST and NDVI data rather than ground-based observations. As a result, the special feature makes it possible for researchers to use numerous types of data, such as NOAA/AVHRR [16], EOS/MODIS [17], and Landsat/ETM+ [18]. Although the TVX method is widely used, it has limitations on sparse vegetation regions where great uncertainty is found [19].

According to many studies, there is a high correlation between the air temperature and LST, and statistical approaches are based upon this relationship [20]. Through linear regression analysis, the method first establishes an experimental equation between air temperatures observed by meteorological stations and LST or brightness temperature of corresponding pixels; then it applies the experimental equation to estimate air temperature in the whole study region. Using data from geostationary satellites, Chen et al. developed a model for simulating surface air temperature at night [21]. Validation results showed a high correlation coefficient of 0.87 and a standard deviation of $1.57 \mathrm{~K}$. Jones et al. used MODIS data to build quantitative relationships between LST and surface air temperature for different geomorphologic types and then applied the quantitative relationships to derive surface air temperature [22]. Results showed that correlation coefficients were from 0.57 to 0.81 , and the RMSE were below $0.74 \mathrm{~K}$. Kawashima et al. estimated surface air temperature on the basis of LST derived from Landsat TM, and results showed that the standard error was within $1.85 \mathrm{~K}$ [12]. Statistical approaches are simple in principle and convenient to use; however, the modeling highly depends on the time and location of the data caption.
Neural network approaches use plenty of neurons linked to each other to simulate any complicated and nonlinear relationships. Without knowing the physical mechanism among surface air temperature, brightness temperature, and land surface properties, neural network approaches establish relationship between surface air temperature and the input variables by training data alone. Using the AVHRR image, surface elevation and solar zenith angle, together with Julian day as neurons, Jang et al. applied neural network approaches to estimate surface air temperature, and the RMSE of estimates was $1.79^{\circ} \mathrm{C}[10]$. Zhao et al. used the albedo, NDVI, DEM, and LST as inputs to the neural network approaches to calculate the daily averaged surface air temperature and the daily maximum and the daily minimum air temperature, and the results indicated that the RMSE was about $0.9^{\circ} \mathrm{C}$ [23]. Although the method has obvious advantages in expressing the nonlinear relationship between surface air temperature and other variables, it is limited for inputting a large amount of data $[11,24]$.

Energy and mass exchanging is happening between the land surface and the atmosphere. Without considering the energy transported by horizontal advection and consumed by photosynthesis, the exchange of energy can be described by the energy balance equation:

$$
R_{n}=H+L E+G
$$

where $R_{n}$ is the net radiation, $H$ is the sensible heat flux, $L E$ is the latent heat flux, and $G$ is the soil heat flux; units of the four items are $\mathrm{W} / \mathrm{m}^{2}$. Both the sensible heat flux and the latent heat flux can be regarded as functions of LST and surface air temperature and soil heat flux can be expressed by the net radiation. Through formula derivation, the expression of surface air temperature which contains LST and other land surface variables can be obtained [13]. Using observations at weather stations, surface vegetation, and geomorphology information as inputs to the energy balance equation, Pape and Löffler estimated surface air temperature in the alpine areas [25]. The RMSE of the estimates in their study was between 0.37 and $1.02^{\circ} \mathrm{C}$. Zakšek and Schroedter-Homscheidt applied the energy balance equation to estimate surface air temperature [11]. It turned out that $88 \%$ of the estimates had absolute deviations within $3^{\circ} \mathrm{C}$. The energy balance equation is a physical method with a good portability. However, it needs a large number of variables, and some of the variables, such as aerodynamic resistance and surface roughness, are difficult to acquire by remote sensing. In addition, the presence of advection always characterizes exchanges in near surface layer and contributes to the uncertainty of energy influxes, especially heat storage change; that is to say, the advection would affect the energy balance equation and should be discussed as one of the reasons of energy balance imbalance. That means item $\left(R_{n}\right)$ on the left side of (1) is not equal to items $(H+L E+G)$ on the right side of $(1)[26,27]$.

In conclusion, approaches to estimate surface air temperature from remote sensing are usually based on statistical, empirical, and energy balance models. Su et al. proposed an algorithm to expand the surface air temperature to a larger spatial domain, which is based on the fact that 
the variation of surface air temperature is controlled jointly by the local turbulence of radiant driving force and the horizontal advection of the advective driving force [2]. Zhang et al. developed a model called advection-energy balance for air temperature (ADEBAT) model which is based on the theory put forward by $\mathrm{Su}$ et al. [2]. The ADEBAT model assumes that surface air temperature is composed of two parts, the local air temperature and the exotic air temperature [28]. The former is dominated by the radiation effect and mainly indicates the heating effect of longwave radiation on near-surface atmosphere, and this part can be described by the energy balance equation. The latter is caused by the turbulent flow exchange including the turbulent diffusion and exchange of the horizontal advection. Regarding the latter part, an advection factor $f$ is defined to measure the quantity of the exotic air. According to the ADEBAT model, Zhang et al. retrieved the surface air temperature in north China, with an $R^{2}$ higher than 0.77 and an RMSE lower than 0.42 K [28].

The objective of the paper is to improve the ADEBAT model in expanding the advection factor $f$. In the original ADEBAT model, $f$ would be shown as blocks with constant values, which is not correct because the advection also has spatial heterogeneity like other geographical elements. The advection factor $f$ is affected by the intensity of the advective driving force and will make influence on other places by diffusion. Hence, the spatial distribution of $f$ is interpolated by the IDW method in the IADEBAT model.

The outline of this paper is as follows. Section 2 gives a brief description of the ADEBAT model and presents the improvement on $f$ of the IADEBAT model. Section 3 describes the study area and the data. Results of the surface air temperature estimation are presented and analyzed in Section 4. The conclusion and discussion are displayed in Sections 5 and 6, respectively.

\section{Methodology}

2.1. The ADEBAT Model. In this section, the advectionenergy balance for air temperature (ADEBAT) model is briefly introduced. The basic idea of the ADEBAT model [28] is as follows. The surface air temperature is determined by two physical processes, the heating effect produced by the longwave radiation from land surface and the advective effect resulting from the turbulent flow exchange. The two effects are also called the local driving force and the advective driving force, respectively. For the former, surface air temperature increases with the accumulation of absorbing surface longwave radiation. For the latter, the advection disturbs the surface air temperature by the turbulent diffusion exchange which develops between land surface and nearsurface atmosphere.

Assuming there is one cubic meter of air, the temperature of it is dominated only by the heating effect from land surface, which corresponds to a namely surface energy balance closure. In this case, the surface air temperature $T_{a}$ is equal to the local air temperature $T_{\text {loc }}$. However, the energy is imbalanced for the advective effect in most situations [29]. The exotic air comes into the one cubic meter and mixes up with the local air in it. If the air temperature driven by the advective effect due to the exotic energy is defined as $T_{\text {exo }}$, then the actual air temperature $T_{a}$ is a mixture of $T_{\text {loc }}$ and $T_{\text {exo }}$. In order to retrieve the surface air temperature, variables related to the two physical processes need to be determined.

2.1.1. Obtaining the Surface Air Temperature $T_{a}$. Two situations are treated differently when calculating $T_{a}$ : energy balance closure and energy balance misclosure.

In the case of energy balance closure, namely, the surface air temperature is controlled by local driving force only. The exchange of energy is described by the energy balance equation (1). The sensible heat flux (see (2)) and the definition of the Bowen ratio $\beta$ (see (3)) are as follows:

$$
\begin{aligned}
H & =\frac{\rho C_{p}}{r_{a}}\left(T_{0}-T_{a}\right), \\
\beta & =\frac{H}{L E},
\end{aligned}
$$

where $\rho C_{p}$ is the volumetric heat capacity of air, $r_{a}$ is the air aerodynamic resistance under the condition of no wind and no advection, and $T_{0}$ is aerodynamic temperature which is usually substituted by LST in applications [30, 31].

By combining (1), (2), and (3), the surface air temperature $T_{a}$ can be derived as

$$
T_{a}=T_{0}-\frac{\beta\left(R_{n}-G\right)}{\beta+1} \frac{r_{a}}{\rho C_{p}} .
$$

Because $T_{a}$ is equal to the local air temperature $T_{\text {loc }}$ under the condition of energy balance closure, hence, $T_{a}$ can be replaced by $T_{\text {loc }}$ in (4), and we attain $T_{\text {loc }}$ as follows:

$$
T_{\mathrm{loc}}=T_{0}-\frac{\beta\left(R_{n}-G\right)}{\beta+1} \frac{r_{a}}{\rho C_{p}} .
$$

In most cases, the surface energy balance of the near surface air is not closed due to the advective driving force. Like windy days, the effect of local driving force on the air temperature becomes less dominant; at the same time the advective driving force would be more dominant. Both the local driving force and the advective driving force have an impact on the $T_{a}$, and $T_{a}$ is mixed up by $T_{\text {loc }}$ and $T_{\text {exo }}$. Provided that the mixing satisfies the linear mixed theory, $T_{a}$ can be calculated as

$$
\begin{aligned}
T_{a} & =f T_{\mathrm{exo}}+(1-f) T_{\mathrm{loc}} \\
f & =\frac{V_{\mathrm{exo}}}{V_{a}}, \\
1-f & =\frac{V_{\mathrm{loc}}}{V_{a}},
\end{aligned}
$$

where $T_{a}$ is the real air temperature and $f$ is the volume ratio that is also known as the advection factor. $V_{a}$ is the air volume that equals the sum of $V_{\text {exo }}$ and $V_{\text {loc }} ; V_{\text {exo }}$ and $V_{\text {loc }}$ are the volumes of the exotic air and the local air after the mixing, respectively. Because $f$ is the proportion of mixture, it ranges from 0 to 1 . When $f=0$, it means there is no exotic air that 
corresponds to the situation of energy balance closure, and $T_{a}$ equals $T_{\text {loc }}$. If $f=1$, it indicates that the exotic air entirely replaces the local air. In practice, the vast majority of cases is $0<f<1$.

2.1.2. Obtaining the Proportion of Mixture $f$. In order to calculate $T_{a}$, two other variables, $f$ and $T_{\text {exo }}$, need to be acquired (as in (6)) with the aid of air temperature, wind speed, and wind direction observed at meteorological stations. Assuming the subscript $i$ represents any pixel in the study area, for $f_{(i)}$ and $T_{\operatorname{exo}(i)}$ to be calculated, we firstly identify two nearest meteorological stations which have the similar wind speed and wind direction, because it is supposed that similar wind speed and wind direction supply similar advection. The two pixels covering the two meteorological stations are expressed as Pixel 1 and Pixel 2; then we obtain the relationship below: $f_{(2)}=f_{(1)}=f_{(i)}, T_{\operatorname{exo}(2)}=T_{\operatorname{exo}(1)}=T_{\operatorname{exo}(i)}$ [28]. Based on (6), two new relationships can be derived:

$$
\begin{aligned}
& T_{a(1)}=f_{(1)} T_{\operatorname{exo}(1)}+\left(1-f_{(1)}\right) T_{\operatorname{loc}(1)}, \\
& T_{a(2)}=f_{(2)} T_{\operatorname{exo}(2)}+\left(1-f_{(2)}\right) T_{\operatorname{loc}(2)},
\end{aligned}
$$

where $T_{a(1)}$ and $T_{a(2)}$ are air temperatures of the two weather stations, respectively. $T_{\operatorname{loc}(1)}$ and $T_{\operatorname{loc}(2)}$ are local air temperatures driven by the local driving force, respectively, and can be calculated by (4) and (5); then $f$ and $T_{\text {exo }}$ of Pixel $i$ can be obtained by solving (9):

$$
\begin{aligned}
f_{(i)} & =f_{(1)}=f_{(2)}=1-\frac{T_{a(1)}-T_{a(2)}}{T_{\operatorname{loc}(1)}-T_{\operatorname{loc}(2)}}, \\
T_{\operatorname{exo}(i)} & =T_{\operatorname{exo}(1)}=T_{\operatorname{exo}(2)} \\
& =\frac{\left(T_{a(1)}+T_{a(2)}\right)-\left(1-f_{(i)}\right)\left(T_{\operatorname{loc}(1)}+T_{\operatorname{loc}(2)}\right)}{f_{(i)}} .
\end{aligned}
$$

After solving $f_{(i)}$ and $T_{\operatorname{exo}(i)}$ by (10) at every pixel, $T_{a}$ at every pixel can be obtained by (6).

2.2. Improvement on the ADEBAT Model. According to formula derivation in Section 2.1.2, we know that every inputted meteorological station would get an advection factor by solving (10). For two nearest weather stations with similar wind speed and similar wind direction, that is, with similar advection, pixels around them would use the same advection factor, so the result of the advection factor would be shown as blocks with constant value which are stations-centered. This is how to get $f$ in the ADEBAT model. However, the result of $f$ acquired by the ADEBAT model is unreasonable for spatial heterogeneity. Hence, it is necessary to make improvement on obtaining the spatial distribution of $f$. The IADEBAT model uses the IDW method to expand the ground-based $f$ from a point scale to a regional scale to obtain the spatial distribution of $f$. The reason for applying the IDW method

\begin{tabular}{|c|c|c|c|c|}
\hline \multirow{2}{*}{$\begin{array}{c}f \text { shown as } \\
\text { blocks }\end{array}$} & ADEBAT & \multirow{2}{*}{ Site-based $f$} & IADEBAT & \multirow{2}{*}{$\begin{array}{c}f \text { shown as } \\
\text { gradient }\end{array}$} \\
\hline & Equation (10) & & IDW & \\
\hline
\end{tabular}
can be described as follows.

The advection factor $f$ is affected by the intensity of the advective driving force which goes to other places by diffusion. As a result, to the advective driving force of a certain
FIGURE 1: The sketch on difference between the ADEBAT model and the IADEBAT model.

station, with increasing the distance from the station, the advection factor is becoming less affected by it. Since the IDW method interpolates according to the distance between two inputted objectives, it is appropriate to obtain the spatial distribution of the advection factor by the IDW method. Formulas can be written as

$$
\begin{aligned}
f_{(i)} & =\sum_{x=1}^{n} w_{(x)} f_{(x)}, \\
w_{(x)} & =\frac{1 / d_{x}{ }^{k}}{\sum_{x=1}^{n} 1 / d_{x}{ }^{k}},
\end{aligned}
$$

where $f_{(i)}$ is the advection factor of any pixel to be calculated, $x$ is the number of the inputted meteorological station, $f_{(x)}$ is the advection factor of the station number $x, w_{(x)}$ is the weight, $d_{x}$ is the distance between Pixel $i$ and the station number $x$, and $k$ is the specified power exponent. Different from the ADEBAT model, the IADEBAT model would get gradual distribution results of $f$. Figure 1 gives the sketch on difference between models of the ADEBAT and the IADEBAT.

\section{Study Area and Data}

3.1. Study Area. The study area is located in Zhangye, Gansu, China, and ranges from $38.83^{\circ} \mathrm{N}$ to $38.93^{\circ} \mathrm{N}$ in latitude and from $100.32^{\circ} \mathrm{E}$ to $100.42^{\circ} \mathrm{E}$ in longitude (Figure 2), which is in the core oasis of middle reaches of the Heihe River. Major features of the climate here are dry and rainless. The annual mean temperature is $7.0^{\circ} \mathrm{C}$ and the annual mean precipitation is $124.9 \mathrm{~mm}$. The potential evaporation, more than $2000 \mathrm{~mm}$, is much higher than the precipitation. The land cover in the study area mainly consists of cropland cultivated with seed corn, vegetables, apple orchards, and windbreak forests, as well as with some built-up areas (villages) scattered throughout. From May to September, seed corn is the staple crop in the study area, and there are also small areas of vegetables and fruit trees. Since it is arid, almost all the farmlands are irrigated with the water from the Heihe River, and the study area belongs to irrigation districts with alternating irrigation regimen.

3.2. Remote Sensing Data. The ASTER images and HJ-1A/B images (the small satellite constellation for environment and disaster monitoring and forecasting) were utilized in the study for acquiring variables including surface albedo $\alpha$, surface emissivity $\varepsilon_{s}$, vegetation fraction $f_{v}$, and LST. The four variables were aiming to calculate the net radiation $R_{n}$, soil heat flux $G$, and the local air temperature $T_{\text {loc }}$. The ASTER is a sensor collecting multispectral visible, near-infrared, and thermal infrared images, and it is a special remote sensing tool intended to monitor land surface energy balance, 


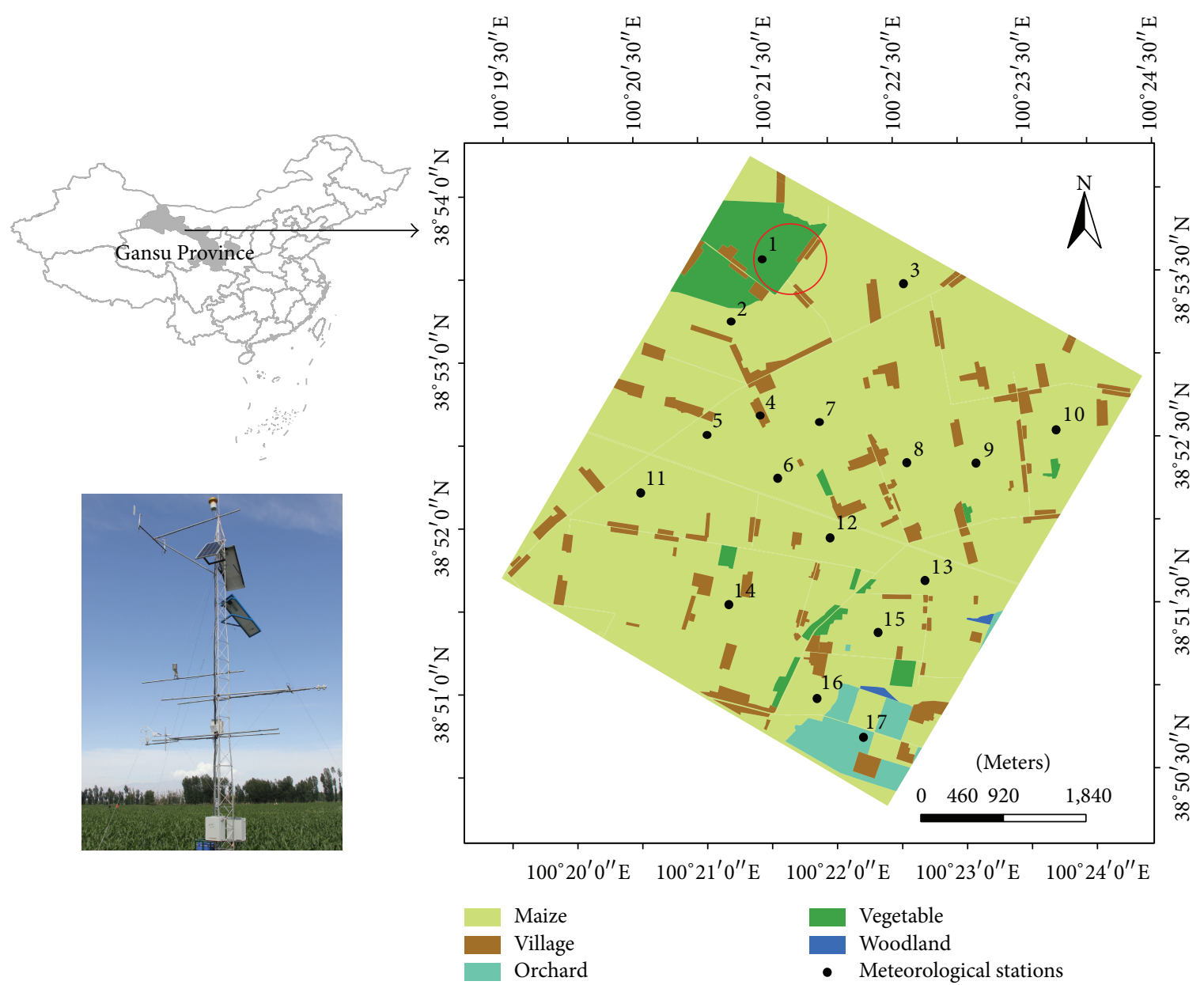

FIGURE 2: Land use status in the study area and spatial distribution of meteorological stations.

hydrological processes, and climate [32]. From the ASTER images, the vegetation fraction $f_{v}$, surface emissivity $\varepsilon_{s}$, and LST (based on method presented by [33]) were obtained. The surface albedo $\alpha$ was from products provided by [34], and the albedo products were calculated from images acquired from HJ-1A/B which was launched by China in 2008, with two CCDs carried by each satellite, and every 3 or 4 days the satellite could revisit the same place.

3.3. Meteorological Data. Meteorological data is supported by the experiment named HiWATER, which is a watershed scale eco-hydrological experiment designed from an interdisciplinary perspective to address problems that include heterogeneity, scaling, uncertainty, and closing of the water cycle at the watershed scale $[35,36]$. The experiment was performed in the Heihe River Basin which is in the arid region of northwest China. The data now is shared online, and users can get data by submitting application to Cold and Arid Regions Science Data at Lanzhou (http://westdc.westgis.ac.cn/).

There are 17 Automatic Weather Stations (AWS) in the study area, as shown in Figure 2. They were all with automatic data acquisition systems, and sample intervals of the data were 1 and 10 minutes. Air temperature, humidity, wind speed, wind direction, air pressure, land surface temperature,
TABLE 1: General descriptions of the variables and sources.

\begin{tabular}{lc}
\hline Variables & Sources \\
\hline LST at satellite passing time & ASTER \\
Albedo & HJ-1A/B \\
$f_{v}$ & ASTER \\
$\mathcal{\varepsilon}_{s}$ & ASTER \\
Solar radiation & Meteorological stations \\
\hline
\end{tabular}

and solar radiation were observed. In order to estimate $f$ and $T_{\text {exo }}$, six meteorological stations selected randomly were utilized as inputs, and the other stations were used to validate the estimations of air temperature. Variables and sources applied in the study are listed in Table 1.

Two clear sky days chosen to conduct the study are June 24th and July 10th, 2012. To evaluate the results retrieved by the IADEBAT model and make an objective assessment on it, estimates by the other two methods, the ADEBAT model and the IDW method, were provided for comparing.

\section{Results}

By using remote sensing data and meteorological data as inputs to the three methods, the spatial distributions of 

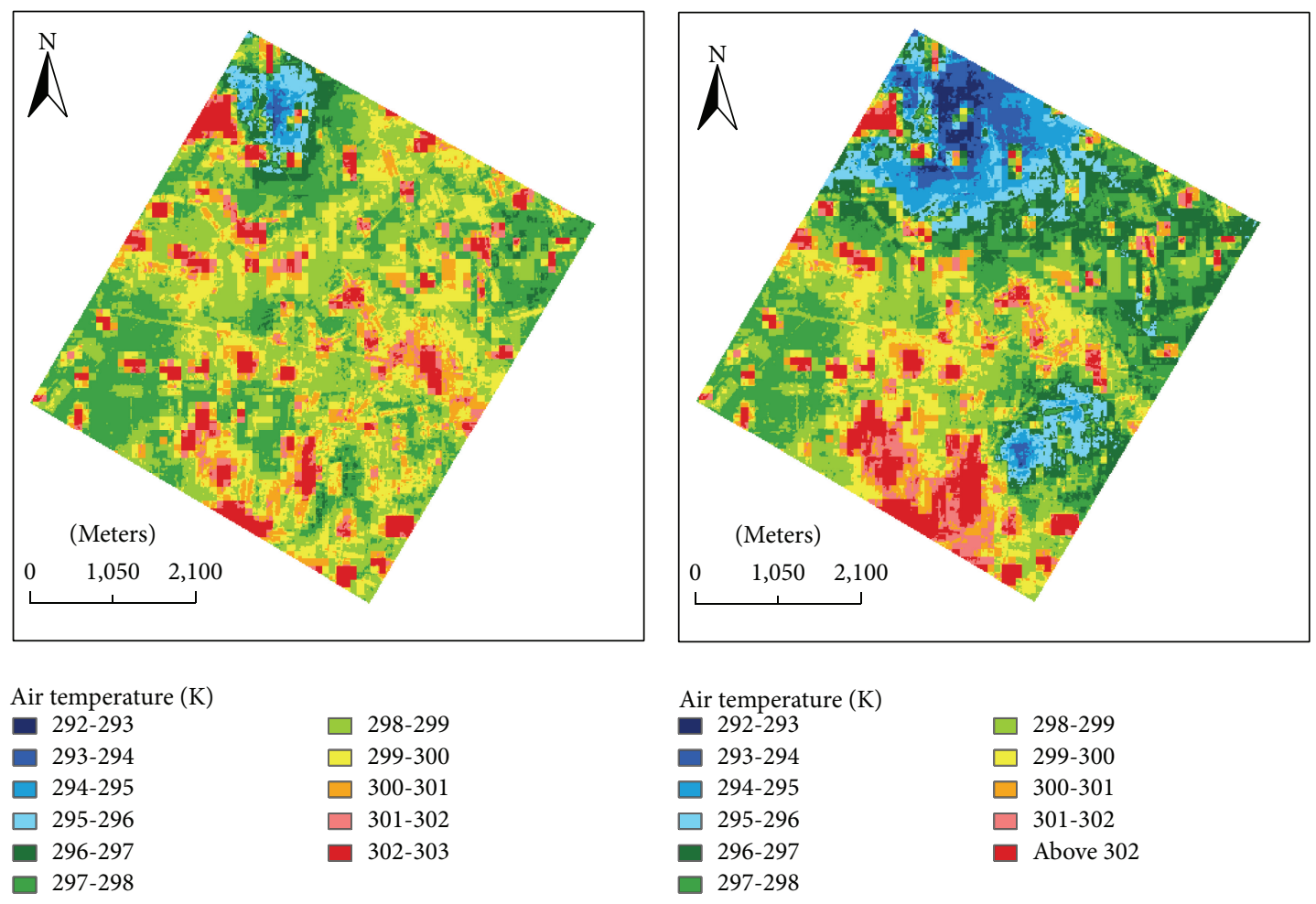

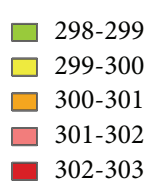

(a)

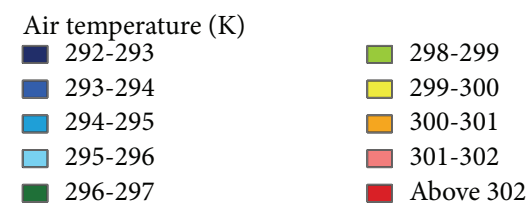

(b)

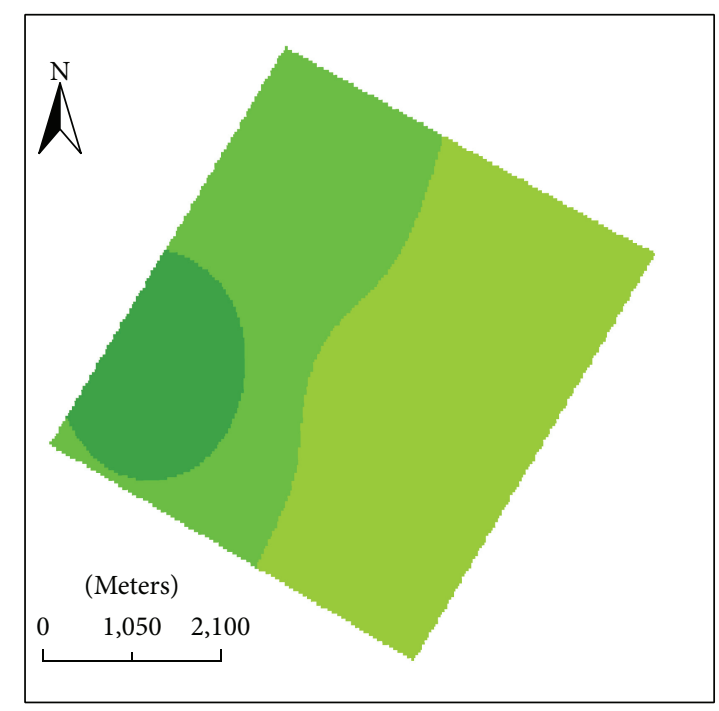

Air temperature (K)
$\square 297.5-298$
$\square 298-298.5$
$\square 298.5-299$

(c)

Figure 3: Air temperature retrieved by the IADEBAT model (a), the ADEBAT model (b), and the IDW method (c) on June 24 th, 2012.

surface air temperature were finally retrieved. Figure 3 shows the inverted results based on the IADEBAT model (a), the ADEBAT model (b), and the IDW method (c) on June 24th, 2012. Similarly, estimates on July 10th, 2012, are shown in Figure 4.
4.1. Analysis on Results Interpolated by the IDW Method. Interpolations by the IDW method were without detailed textures, and the estimated values are between weather stations with high air temperature and those with low temperature. Otherwise, the high temperature and low temperature occur 

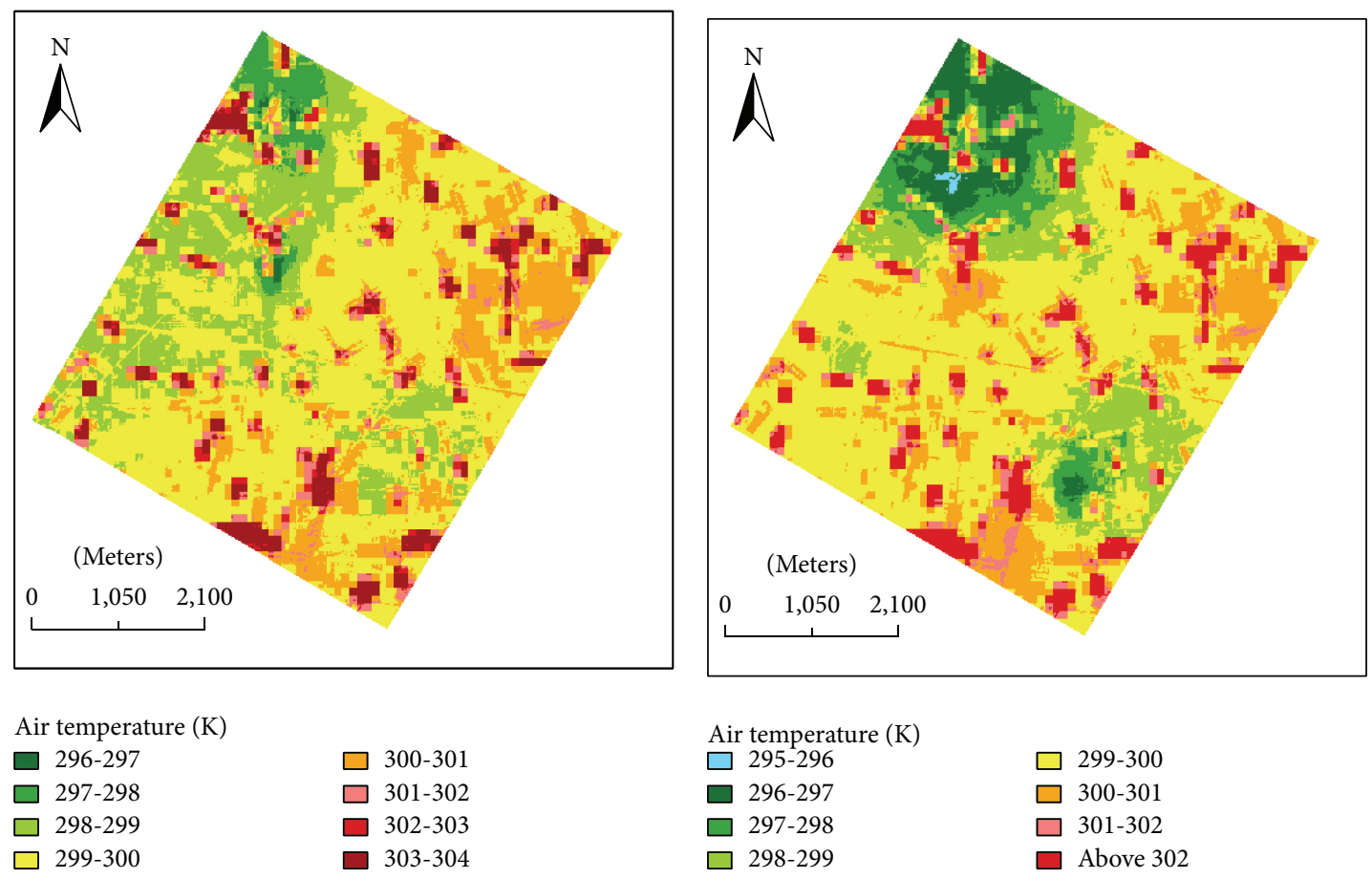

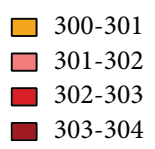

(a)

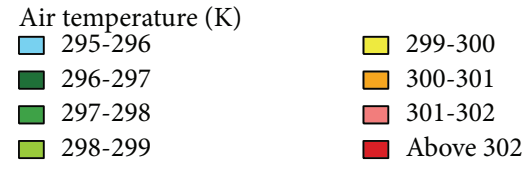

(b)
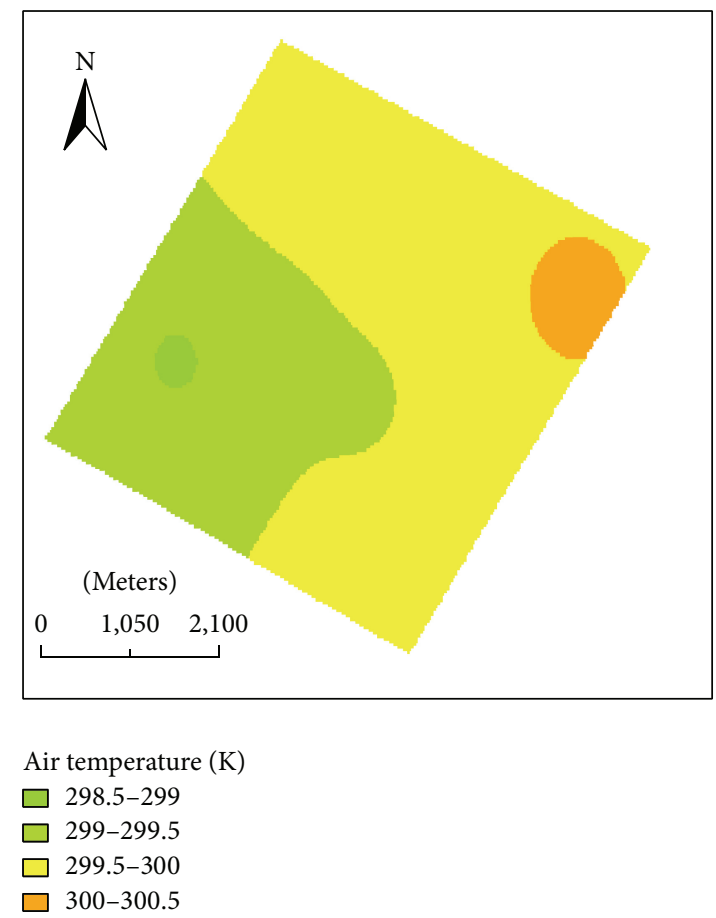

(c)

FIgURE 4: Air temperature retrieved by the IADEBAT model (a), the ADEBAT model (b), and the IDW method (c) on July 10 th, 2012.

in the form of circular high temperature area and low temperature area, and this spatial pattern displayed by the IDW method does not exist actually. The IDW method just considers the advective driving force but ignores the local driving force, so results interpolated by the IDW method fail to describe the true distribution of surface air temperature.
Taking the red circle area in Figure 2 as an example, it was irrigated in the way of traditional constant flooding from 12:00 pm June 22nd to 12:00 pm June 24th, 2012. The irrigation water was snow melt water about $15^{\circ} \mathrm{C}$ from Qilian Mountain and transferred by the Heihe River. Because the wind speed in the study area on June 24th, 2012, was rather low, about 
TABLE 2: Air temperatures measured by meteorological stations and retrieved by the IADEBAT and the ADEBAT models from three different land use types on June 24th, 2012.

\begin{tabular}{|c|c|c|c|c|c|}
\hline \multirow{2}{*}{ Land use } & \multirow{2}{*}{ Observations } & \multicolumn{2}{|c|}{ IADEBAT (K) } & \multicolumn{2}{|c|}{$\operatorname{ADEBAT}(\mathrm{K})$} \\
\hline & & Estimations & $T_{a \text {-est }}-T_{a \text {-obs }}$ & Estimations & $T_{a \text {-est }}-T_{a \text {-obs }}$ \\
\hline Village & 299.7 & 302.0 & 2.3 & 302.3 & 2.6 \\
\hline Maize & 298.5 & 298.5 & 0 & 297.0 & -1.5 \\
\hline Orchard & 298.9 & 299.8 & 0.8 & 300.0 & 1.1 \\
\hline
\end{tabular}

Note: $T_{a \text {-est }}$ means air temperature is estimated by the model; $T_{a \text {-obs }}$ means air temperature is observed by meteorological stations.

TABLE 3: Air temperatures measured by meteorological stations and retrieved by the IADEBAT and the ADEBAT models from three different land use types on July 10th, 2012.

\begin{tabular}{|c|c|c|c|c|c|}
\hline \multirow{2}{*}{ Land use } & \multirow{2}{*}{ Observations } & \multicolumn{2}{|c|}{ IADEBAT $(\mathrm{K})$} & \multicolumn{2}{|c|}{$\operatorname{ADEBAT}(\mathrm{K})$} \\
\hline & & Estimations & $T_{a \text {-est }}-T_{a \text {-obs }}$ & Estimations & $T_{a \text {-est }}-T_{a \text {-obs }}$ \\
\hline Village & 299.3 & 299.5 & 0.2 & 302.1 & 2.8 \\
\hline Maize & 298.9 & 298.9 & 0 & 300.1 & 1.2 \\
\hline Orchard & 299.9 & 299.8 & -0.1 & 301.2 & 1.3 \\
\hline
\end{tabular}

$1.4 \mathrm{~m} / \mathrm{s}$, which means the advective driving force was weak but the local driving force was in dominant position, there would be a low temperature area surrounding the red circle (as shown in Figure 3(a)). However, the IDW method cannot represent this information, because the area is between two interpolated weather stations with relative high temperatures.

4.2. Analysis on Results Retrieved by the IADEBAT and the ADEBAT Models. Comparing to the IDW method, the IADEBAT and the ADEBAT models take into account effects including not only the advection driving force, but also the local driving force on near surface air. It is obvious that surface air temperature retrieved by both models provides a wealth of information in detailed features. In addition, the IADEBAT and the ADEBAT models can express low temperature regions, such as water area, and can display high temperature regions, such as built-up areas (villages), exactly. Referring to low air temperature region, the irrigated area on June 24th, 2012, can be used as an example. The air temperature of the irrigated area must be lower than surrounding regions (as shown in Figures 3(a) and 3(b)), because the area had been irrigated for more than two days by low temperature water and was mainly controlled by local driving force. About high temperature regions, built-up areas (villages) were taken as examples. On both two days, built-up villages showed high air temperature.

4.3. Comparison between the IADEBAT and the ADE$B A T$ Models. The comparisons were made between results acquired from the IADEBAT and the ADEBAT models. In order to assess the accuracy of the two methods, three different land use types were chosen to analyze. Tables 2 and 3 give the observations and estimations of air temperature acquired by meteorological stations and the two methods. From Tables 2 and 3, we know that the estimation errors of the IADEBAT model are much lower than those of the ADEBAT model. Hence, results obtained by the IADEBAT model are more accurate.
As stated above, we know that the red circle was irrigated from 12:00 pm, June 22nd, to 12:00 pm, June 24th, 2012, so the area around the red circle must have low air temperature. According to alternating irrigation schedule provided by the Water Authority, the irrigation area was largely in line with the low air temperature area obtained by the IADEBAT model (as shown in Figure 3(a)). However, the low air temperature area shown in Figure 3(b) was greatly overestimated by the ADEBAT model; this is because the advection factor $f$ was controlled by the intensity of the advective driving force and the $f$ in the study area should be gradual. However, constant $f$ was used by the ADEBAT model, which is displayed as blocks of the same $f$; hence, the $f$ in the ADEBAT model may be overestimated or underestimated for the reason that the $f$ has spatial heterogeneity and cannot remain the same.

4.4. Validation. In order to validate the results, comparisons were made among results acquired by the three methods, as shown in Figure 5. The correlation coefficient $R^{2}$ between estimations by the IADEBAT model and in situ observations, 0.77 , is higher than that between estimations by the ADEBAT model and corresponding measurements, 0.67, which illustrates that results of the IADEBAT model have better correlation with observations; that is to say, estimates by the IADEBAT model are closer to the 1:1 line. The Root Mean Square Error (RMSE) and Mean Absolute Error (MAE) of the IADEBAT model, $0.31 \mathrm{~K}$ and $0.27 \mathrm{~K}$, respectively, are also lower than those of the ADEBAT model, $0.43 \mathrm{~K}$ and $0.34 \mathrm{~K}$, respectively, which indicates that the accuracy of calculations from the IADEBAT model is better than that from the ADEBAT model. Obviously, results derived by the IDW method, with a correlation coefficient $R^{2}$ of 0.17 , an RMSE of $0.56 \mathrm{~K}$, and a MAE of $0.51 \mathrm{~K}$, are much worse than by the IADEBAT model.

Because statistical indicators, the RMSE of the IADEBAT and of the ADEBAT models, are both below $0.5 \mathrm{~K}$, we do not know whether there is a significant difference between the two models. Hence, it is necessary to use a $t$-test (Paired 
TABLE 4: Paired samples test between MADs of the IADEBAT and of the ADEBAT models.

\begin{tabular}{|c|c|c|c|c|c|c|c|c|}
\hline \multicolumn{9}{|c|}{ Paired difference } \\
\hline & \multirow[t]{2}{*}{ Mean } & \multirow{2}{*}{$\begin{array}{c}\text { Std. } \\
\text { deviation }\end{array}$} & \multirow{2}{*}{$\begin{array}{l}\text { Std. error } \\
\text { mean }\end{array}$} & \multicolumn{2}{|c|}{$\begin{array}{l}95 \% \text { confidence interval } \\
\text { of the difference }\end{array}$} & \multirow{2}{*}{$t$} & \multirow{2}{*}{$\mathrm{df}$} & \multirow{2}{*}{ Sig. (2-tailed } \\
\hline & & & & Lower & Upper & & & \\
\hline $\begin{array}{l}\text { MAD_IADEBAT - } \\
\text { MAD_ADEBAT }\end{array}$ & -0.13947 & 0.32259 & 0.06585 & -0.27568 & -0.00325 & -2.118 & 23 & 0.043 \\
\hline
\end{tabular}

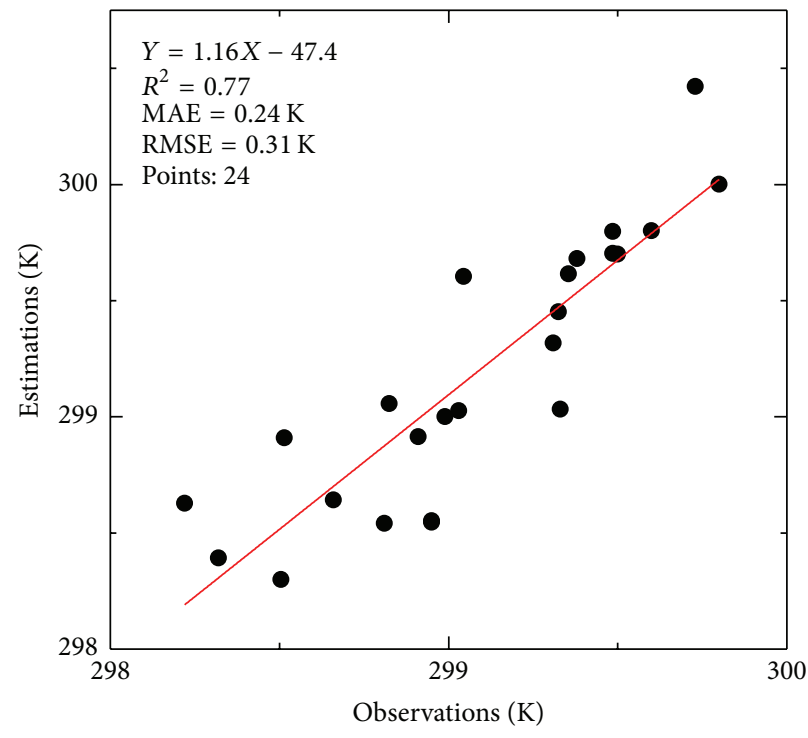

(a)

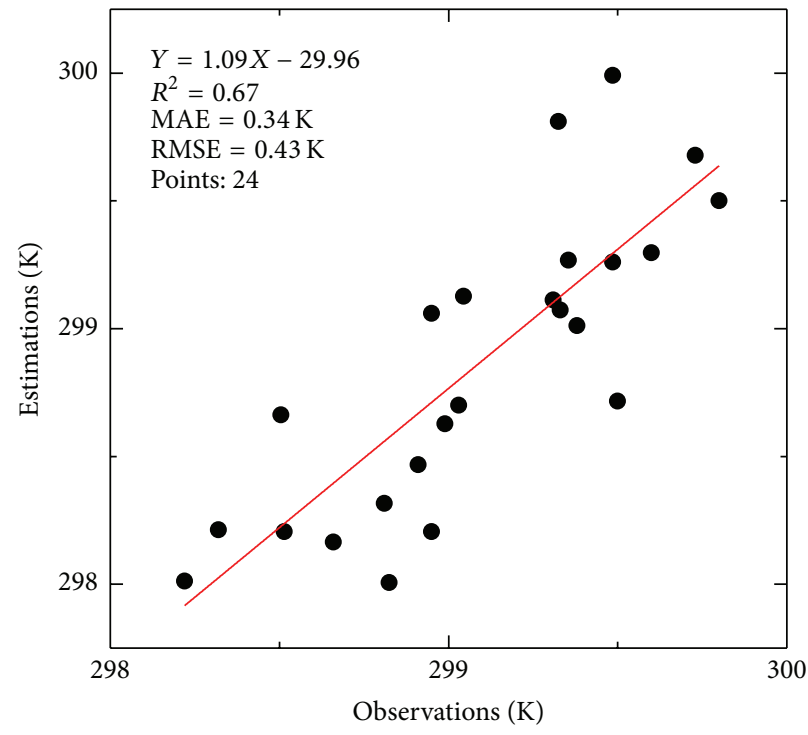

(b)

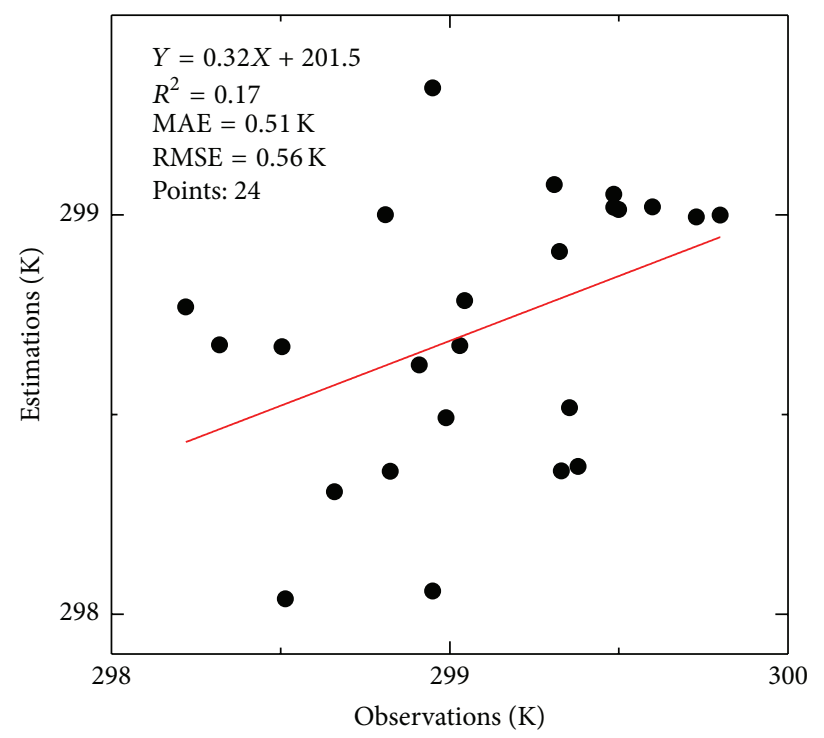

(c)

FIGURE 5: Comparison of air temperature derived from the IADEBAT model (a), the ADEBAT model (b), and the IDW method (c).

Samples Test). Table 4 gives the $t$-test result between MADs of the two models. A 5\% significance level is set as criteria to judge if MAD of the IADEBAT model is significantly lower than that of the ADEBAT model. The Paired Samples Test in Table 4 shows that $p=0.043$, which is lower than 0.05 . As a result, we can draw a conclusion that results obtained by the IADEBAT model have significant lower MAD than that calculated by the ADEBAT model. Because the IADEBAT model also has better correlation indicators $\left(R^{2}, \mathrm{RMSE}\right.$, and $\mathrm{MAE}$ ) than the ADEBAT model, the improved IADEBAT 
model can acquire better estimation of air temperature and the improvement on $f$ is feasible.

\section{Discussion}

The ADEBAT model divides the surface air temperature into two parts that can be obtained by energy balance equation and by meteorological observations, respectively. The idea relies on a clear physical mechanism and is completely different from traditionally interpolation methods, such as IDW which just interpolates according to geostatistics principle and is different from other remote sensing methods, such as the TVX and the statistical approach, which always neglect the formation mechanism of air temperature and consider the air temperature as a whole and are based on empirical relationship. As a result, benefiting from the clear physical meaning, the IADEBAT model has good portability and general applicability and also offers thought for acquiring the spatial distribution of air temperature by remote sensing. Furthermore, the IADEBAT model can acquire the spatial distribution of surface air temperature with a more wealth of detailed textures than traditional geostatistics interpolation methods. Comparing the IADEBAT model with the energy balance method, it also has its merit on the specific air aerodynamic resistance under the condition of no wind and no advection which is an exact value and can be calculated through the laboratory experiment. However, the air aerodynamic resistance used in the energy balance method is in practice difficult to be determined. Hence, the exact value of air aerodynamic resistance used in the IADEBAT model would avoid complex computing process.

However, the IADEBAT model has limitations when an objective evaluation is made because it is highly depending on numerous ground-based observations. If a place has no adequate observations, then the model cannot be applied successfully, and therefore, the application of the IADEBAT model is selective. The amount of ground-based observations used as input or as validation is depending on the size of the study area, the requested accuracy, and the resolution of the remote sensed images. Furthermore, the IADEBAT model is based on the remote sensing data, and hence, it has the generic defects of remote sensing methods. The IADEBAT model cannot be applied on cloudy or rainy days. In the future, it is looking forward to develop interpolation techniques which can take into account both the temporal variation and the spatial variation of surface air temperature to acquire continuous results.

\section{Conclusion}

Remote sensing is a promising tool to get information on the underlying surface, and the IADEBAT model used in the study is a remote sensing method which is based on the formation mechanism of air temperature. It takes into account the local driving force that produces local air temperature and the advective driving force that brings the exotic air temperature. The advection factor $f$ is defined to measure the quantity of the advective driving force. In order to increase the accuracy of the retrieved air temperature, the study makes improvement on the advection factor $f$ of the IADEBAT model which expanded the advection factor $f$ to a regional scale by the IDW method. The IADEBAT model was validated by using observed data and was compared with the ADEBAT model and the IDW method. Verification showed estimations acquired by the IADEBAT model with an $R^{2}$ of 0.77 , an RMSE of $0.31 \mathrm{~K}$, and a MAE of $0.24 \mathrm{~K}$, which had the highest accuracy than estimations acquired by the ADEBAT model and the IDW method that had an $R^{2}$ of 0.67 , an RMSE of $0.43 \mathrm{~K}$, and a MAE of $0.34 \mathrm{~K}$ and an $R^{2}$ of 0.17 , an RMSE of $0.56 \mathrm{~K}$, and a MAE of $0.51 \mathrm{~K}$, respectively. As for the estimation errors, we made analyses on three different land use types. Results indicated that the IADEBAT model had lower estimation errors than the ADEBAT model; that is to say, the IADEBAT model has better accuracy than the ADEBAT model on heterogeneous underlying surfaces. A $t$-test was made between MADs of results obtained by the IADEBAT and the ADEBAT models. The $p(0.043)$ proved that the improvement on the advection factor $f$ was significant. As a result, the improvement proposed in the study is feasible and reasonable.

\section{Competing Interests}

The authors declare no conflict of interests.

\section{Acknowledgments}

This work is supported by the National Natural Science Foundation of China (Grant nos. 41571356, 41271380, and 41171286) and the National Basic Research Program of China (Grant no. 2013CB733406).

\section{References}

[1] L. Prihodko and S. N. Goward, "Estimation of air temperature from remotely sensed surface observations," Remote Sensing of Environment, vol. 60, no. 3, pp. 335-346, 1997.

[2] H. Su, J. Tian, R. Zhang et al., "A physically based spatial expansion algorithm for surface air temperature and humidity," Advances in Meteorology, vol. 2013, Article ID 727546, 8 pages, 2013.

[3] V. Lakshmi, K. Czajkowski, R. Dubayah, and J. Susskind, "Land surface air temperature mapping using TOVS and AVHRR," International Journal of Remote Sensing, vol. 22, no. 4, pp. 643$662,2001$.

[4] T. A. Huld, M. Šúri, E. D. Dunlop, and F. Micale, "Estimating average daytime and daily temperature profiles within Europe," Environmental Modelling and Software, vol. 21, no. 12, pp. 16501661, 2006.

[5] A. D. Hartkamp, K. De Beurs, A. Stein, and J. W. White, Interpolation Techniques for Climate Variables, CIMMYT, 1999.

[6] J. V. Vogt, A. A. Viau, and F. Paquet, "Mapping regional air temperature fields using satellite-derived surface skin temperatures," International Journal of Climatology, vol. 17, no. 14, pp. 1559-1579, 1997.

[7] M. Ninyerola, X. Pons, and J. M. Roure, "A methodological approach of climatological modelling of air temperature and precipitation through GIS techniques," International Journal of Climatology, vol. 20, no. 14, pp. 1823-1841, 2000. 
[8] J. Li and A. D. Heap, "A review of comparative studies of spatial interpolation methods in environmental sciences: performance and impact factors," Ecological Informatics, vol. 6, no. 3-4, pp. 228-241, 2011.

[9] C.-D. Xu, J.-F. Wang, M.-G. Hu, and Q.-X. Li, "Interpolation of missing temperature data at meteorological stations using P-BSHADE," Journal of Climate, vol. 26, no. 19, pp. 7452-7463, 2013.

[10] J. D. Jang, A. A. Viau, and F. Anctil, "Neural network estimation of air temperatures from AVHRR data," International Journal of Remote Sensing, vol. 25, no. 21, pp. 4541-4554, 2004.

[11] K. Zakšek and M. Schroedter-Homscheidt, "Parameterization of air temperature in high temporal and spatial resolution from a combination of the SEVIRI and MODIS instruments," ISPRS Journal of Photogrammetry and Remote Sensing, vol. 64, no. 4, pp. 414-421, 2009.

[12] S. Kawashima, T. Ishida, M. Minomura, and T. Miwa, "Relations between surface temperature and air temperature on a local scale during winter nights," Journal of Applied Meteorology, vol. 39, no. 9, pp. 1570-1579, 2000.

[13] Y.-J. Sun, J.-F. Wang, R.-H. Zhang, R. R. Gillies, Y. Xue, and Y.-C. Bo, "Air temperature retrieval from remote sensing data based on thermodynamics," Theoretical and Applied Climatology, vol. 80, no. 1, pp. 37-48, 2005.

[14] R. R. Nemani and S. W. Running, "Estimation of regional surface resistance to evapotranspiration from NDVI and thermalIR AVHRR data," Journal of Applied Meteorology, vol. 28, no. 4, pp. 276-284, 1989.

[15] S. D. Prince, S. J. Goetz, R. O. Dubayah, K. P. Czajkowski, and M. Thawley, "Inference of surface and air temperature, atmospheric precipitable water and vapor pressure deficit using advanced very high-resolution radiometer satellite observations: comparison with field observations," Journal of Hydrology, vol. 212-213, no. 1-4, pp. 230-249, 1998.

[16] S. J. Goetz, "Multi-sensor analysis of NDVI, surface temperature and biophysical variables at a mixed grassland site," International Journal of Remote Sensing, vol. 18, no. 1, pp. 71-94, 1997.

[17] H. Yan, J. Zhang, Y. Hou, and Y. He, "Estimation of air temperature from MODIS data in east China," International Journal of Remote Sensing, vol. 30, no. 23, pp. 6261-6275, 2009.

[18] C. Wloczyk, E. Borg, R. Richter, and K. Miegel, "Estimation of instantaneous air temperature above vegetation and soil surfaces from Landsat 7 ETM+ data in northern Germany," International Journal of Remote Sensing, vol. 32, no. 24, pp. 91199136, 2011.

[19] K. P. Czajkowski, T. Mulhern, S. N. Goward, J. Cihlar, R. O. Dubayah, and S. D. Prince, "Biospheric environmental monitoring at BOREAS with AVHRR observations," Journal of Geophysical Research Atmospheres, vol. 102, no. 24, pp. 2965129662, 1997.

[20] A. Benali, A. C. Carvalho, J. P. Nunes, N. Carvalhais, and A. Santos, "Estimating air surface temperature in Portugal using MODIS LST data," Remote Sensing of Environment, vol. 124, pp. 108-121, 2012.

[21] E. Chen, L. H. Allen Jr., J. F. Bartholic, and J. F. Gerber, "Comparison of winter-nocturnal geostationary satellite infrared-surface temperature with shelter-height temperature in Florida," Remote Sensing of Environment, vol. 13, no. 4, pp. 313327, 1983.
[22] P. Jones, G. Jedlovec, R. Suggs, and S. Haines, "Using MODIS LST to estimate minimum air temperatures at night," in Proceedings of the 13th Conference on Satellite Meteorology and Oceanography, pp. 13-18, Norfolk, Va, USA, September 2004.

[23] D. Zhao, W. Zhang, and X. Shijin, "A neural network algorithm to retrieve near-surface air temperature from landsat ETM+ imagery over the Hanjiang River Basin, China," in Proceedings of the IEEE International Geoscience and Remote Sensing Symposium (IGARSS '07), pp. 1705-1708, Barcelona, Spain, June 2007.

[24] S. Stisen, I. Sandholt, A. Nørgaard, R. Fensholt, and L. Eklundh, "Estimation of diurnal air temperature using MSG SEVIRI data in West Africa," Remote Sensing of Environment, vol. 110, no. 2, pp. 262-274, 2007.

[25] R. Pape and J. Löffler, "Modelling spatio-temporal near-surface temperature variation in high mountain landscapes," Ecological Modelling, vol. 178, no. 3-4, pp. 483-501, 2004.

[26] R. A. Spronken-Smith, T. R. Oke, and W. P. Lowry, "Advection and the surface energy balance across an irrigated urban park," International Journal of Climatology, vol. 20, no. 9, pp. 10331047,2000

[27] V. Masson, C. S. B. Grimmond, and T. R. Oke, "Evaluation of the town energy balance (TEB) scheme with direct measurements from dry districts in two cities," American Meteorological Society, no. 2000, pp. 1011-1026, 2002.

[28] R. Zhang, Y. Rong, J. Tian, H. Su, Z.-L. Li, and S. Liu, "A remote sensing method for estimating surface air temperature and surface vapor pressure on a regional Scale," Remote Sensing, vol. 7, no. 5, pp. 6005-6025, 2015.

[29] K. Wilson, A. Goldstein, E. Falge et al., "Energy balance closure at FLUXNET sites," Agricultural and Forest Meteorology, vol. 113, no. 1-4, pp. 223-243, 2002.

[30] W. G. M. Bastiaanssen, M. Menenti, R. A. Feddes, and A. A. M. Holtslag, "A remote sensing surface energy balance algorithm for land (SEBAL): 1. Formulation," Journal of Hydrology, vol. 212-213, no. 1-4, pp. 198-212, 1998.

[31] Z. Su, "The Surface Energy Balance System (SEBS) for estimation of turbulent heat fluxes," Hydrology and Earth System Sciences, vol. 6, no. 1, pp. 85-100, 2002.

[32] A. N. French, F. Jacob, M. C. Anderson et al., "Surface energy fluxes with the advanced spaceborne thermal emission and reflection radiometer (ASTER) at the Iowa 2002 SMACEX site (USA)," Remote Sensing of Environment, vol. 99, no. 1-2, pp. 5565, 2005.

[33] Z. Qin, A. Karnieli, and P. Berliner, "A mono-window algorithm for retrieving land surface temperature from Landsat TM data and its application to the Israel-Egypt border region," International Journal of Remote Sensing, vol. 22, no. 18, pp. 37193746, 2001.

[34] L. Qiang, W. Jianguang, W. Shengbiao, and Q. Ying, Albedo Dataset in 30 m-Resolution in the Heihe River Basin in 2012, Heihe Plan Science Data Center, 2014.

[35] X. Li, G. Cheng, S. Liu et al., "Heihe watershed allied telemetry experimental research (HiWater) scientific objectives and experimental design," Bulletin of the American Meteorological Society, vol. 94, no. 8, pp. 1145-1160, 2013.

[36] H. Li, D. Sun, Y. Yu et al., "Evaluation of the VIIRS and MODIS LST products in an arid area of Northwest China," Remote Sensing of Environment, vol. 142, pp. 111-121, 2014. 

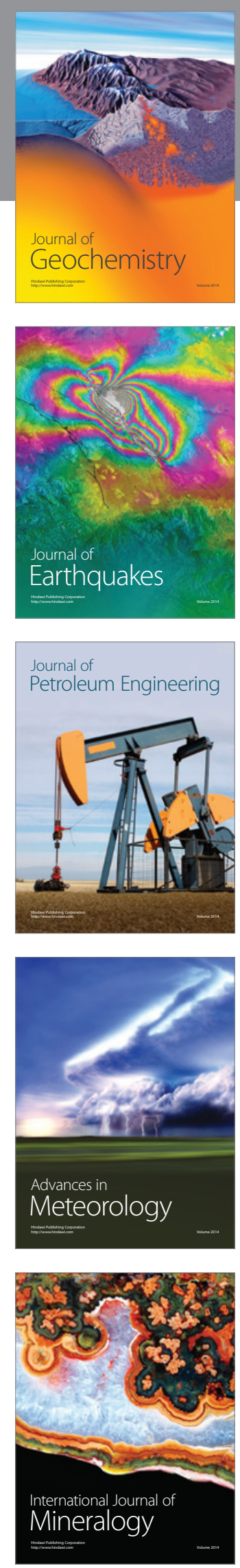
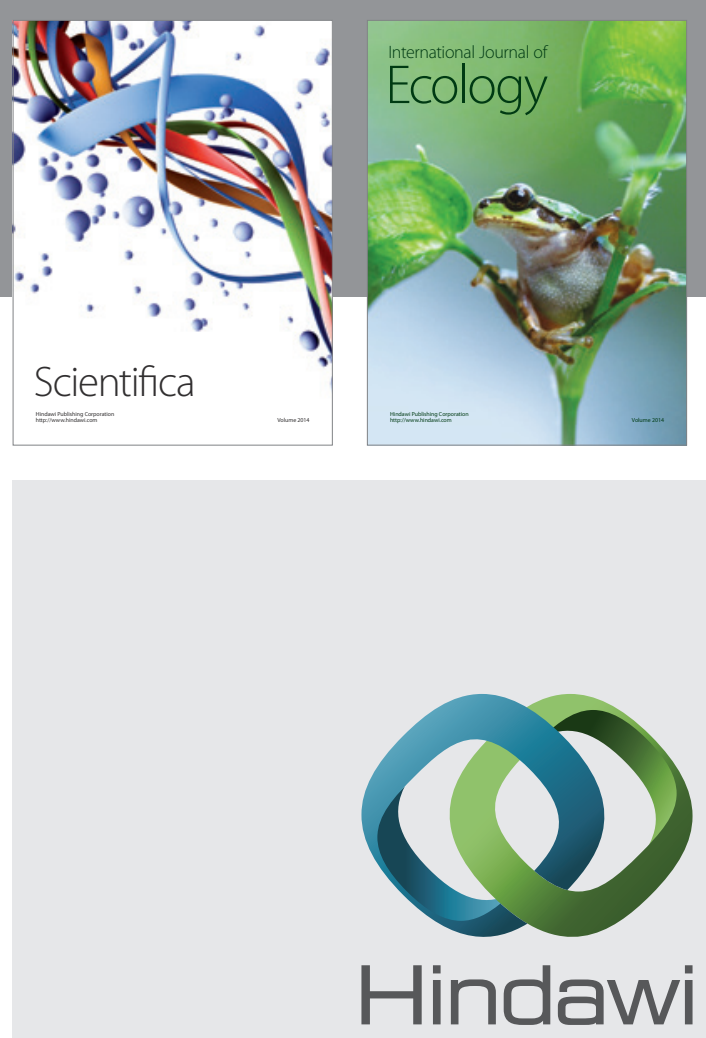

Submit your manuscripts at

http://www.hindawi.com
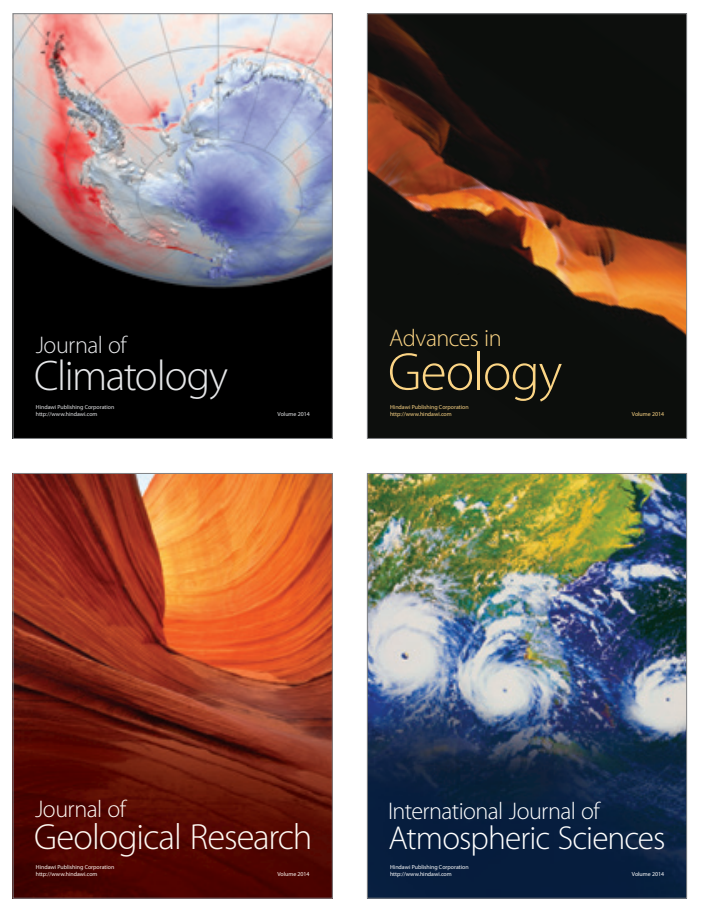

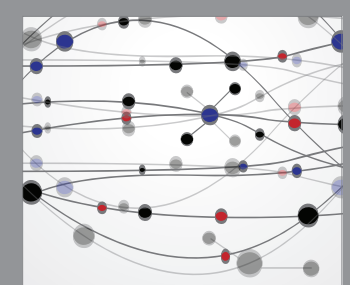

The Scientific

\section{World Journal}
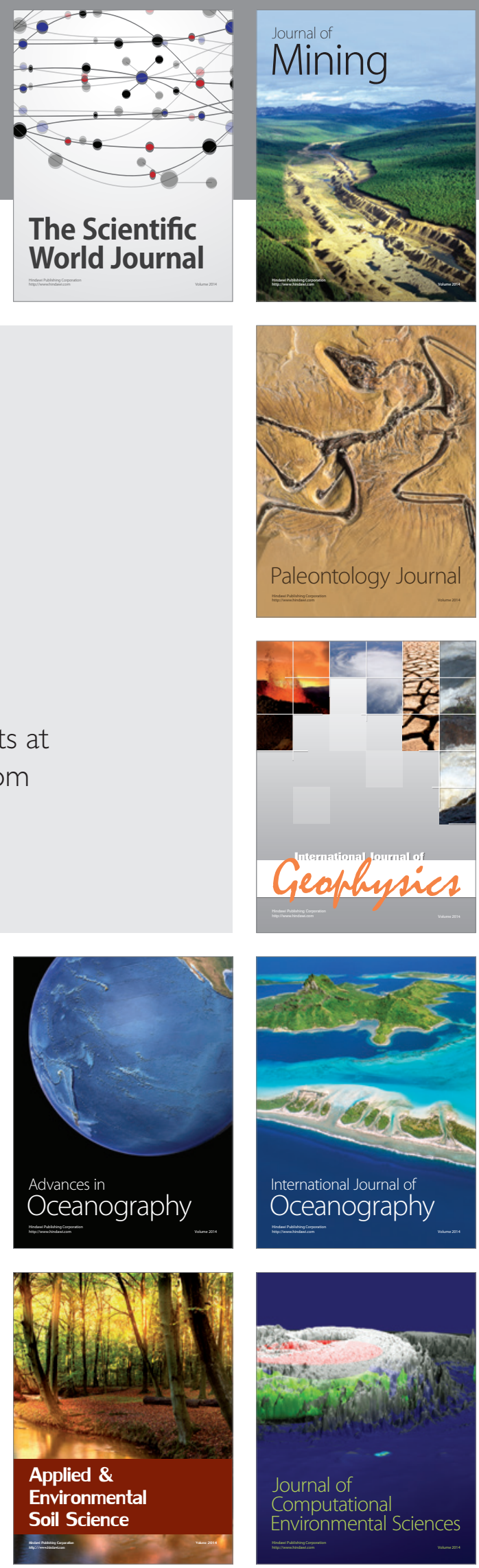